Case Report

\title{
A case report of ventricular septal defect in an adult Sprague Dawley rat
}

\author{
Tetsuro Kurotaki ${ }^{*}$, Yuki Tomonari1 ${ }^{1}$, Junko Sato ${ }^{1}$, Takeshi Kanno1, and Minoru Tsuchitani ${ }^{1}$ \\ 1Pathology Department, Nonclinical Research Center, LSI Medience Corporation, 14-1 Sunayama, Kamisu-shi, Ibaraki 314-0255, \\ Japan
}

\begin{abstract}
A 20-week-old male Sprague Dawley rat noted with decreased body weight, dyspnea, and anorexia beginning 2 days before death was necropsied in the recovery period of a sub-chronic toxicity study. The heart was severely enlarged $(30 \times 20 \times 20 \mathrm{~mm}), 3-4$ times larger than normal, with an approximately $6 \mathrm{~mm}$ wide defect in the upper, membranous portion of the ventricular septum. Both ventricles measured $4 \mathrm{~mm}$ in thickness, and the right ventricle was 4 times thicker than normal. According to a microscopic examination, the myocardial fibers were severely hypertrophic in the right ventricle and mildly hypertrophic in the left ventricle and septum. Myocardial vacuolation, focal hemorrhages with hemosiderin-laden macrophages, myocardial necrosis, focal fibrosis, hyalinized myocardial fibers, and multifocal adhesive pericarditis were also present. This is the first report concerning severe ventricular septal defects in an adult Sprague Dawley rat with a detailed histopathological examination. (DOI: 10.1293/tox.2016-0073; J Toxicol Pathol 2017; 30: $327-332)$
\end{abstract}

Key words: congenital heart anomaly, histopathology, spontaneous, Sprague Dawley rat, ventricular septal defect

A ventricular septal defect (VSD) indicates failure of complete development of the interventricular septum that allows shunting of blood between the ventricles ${ }^{1}$. The defect more commonly occurs in the upper part of the interventricular septum resulting from fusion failure of the membranous and muscular components ${ }^{1-3}$.

VSD is present not only in humans but also in many animals such as horses, ruminants, pigs, dogs, cats, and laboratory animals ${ }^{1}$. Rats, mice, and rabbits have been used as treatment-induced VSD models for evaluation of human congenital heart disease ${ }^{4-7}$, which can be induced experimentally by agents that delay fusion of the cardiac septae. These include various chemicals, such as trypan blue, salicylate $^{2}$, dimethadione ${ }^{8}$, and trimethadione ${ }^{5}$; hypoxia; deficiencies of nutrients, such as vitamin A and folic acid; and nutritional excesses, such as vitamin A and copper excess ${ }^{2}$.

Spontaneous cardiac VSD has been reported in IS/ $\mathrm{Kyo}^{9}$ and Sprague Dawley (SD) rats ${ }^{10}$, specifically in fetal rats with a small VSD. To our knowledge, there are no reports of VSD in adult SD rats with detailed histopathological findings. Our report describes pathological findings of

Received: 29 November 2016, Accepted: 24 May 2017

Published online in J-STAGE: 1 July 2017

*Corresponding author: T Kurotaki

(e-mail: kurotaki.tetsurou@ma.medience.co.jp)

(C2017 The Japanese Society of Toxicologic Pathology

This is an open-access article distributed under the terms of the

Creative Commons Attribution Non-Commercial No Derivatives (by-nc-nd) License. (CC-BY-NC-ND 4.0: https:/
VSD in an adult SD rat with a severe defect in the ventricular septum.

A 20-week-old male Crl:CD(SD) rat was used as a control, in which the vehicle was administered by gavage, in a toxicity study for 13 weeks followed by a 4-week recovery period. This animal was supplied by Charles River Laboratories Japan, Inc. (Kanagawa, Japan). The animal was housed and cared for according to the principles outlined in the guidelines for the care and use of laboratory animals prepared by the Japanese Association for Laboratory Animal Science and our laboratory.

Decreased body weight, dyspnea, and anorexia were noted in the rat beginning 2 days before death. An autopsy was performed a few hours after death. All tissues were fixed in $10 \%$ phosphate-buffered formalin, trimmed, processed, and embedded in paraffin according to the standard of procedure (SOP) of LSI Medience Corporation. Deparaffinized sections were stained with hematoxylin and eosin (HE), and Masson trichrome stain was applied in the heart. Since we judged that the histological findings did not reflect the cause of the severely enlarged heart after slide preparation, the heart tissue was taken out from the paraffin block by reversing the course of embedding, and it was then reexamined macroscopically.

Macroscopic findings: The heart was severely enlarged $(30 \times 20 \times 20 \mathrm{~mm})$, with pericardial adhesion over a wide area. On the embedding plane of the retrieved heart tissue cut longitudinally from base to apex, the heart was 3-4 times larger than normal, and no anomalies were identified in the heart (Fig. 1). The wall thicknesses were 2.5, 2.0, and 


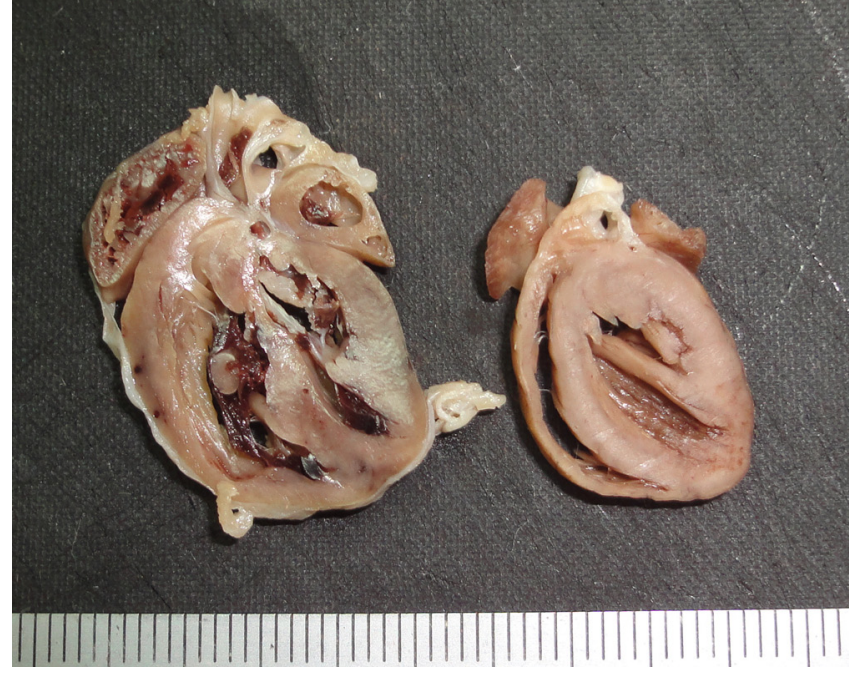

Fig. 1. On the embedding plane of retrieved heart tissue cut longitudinally from base to apex, the VSD heart is severely enlarged (left), 3-4 times larger than normal (right, 13-week-old).

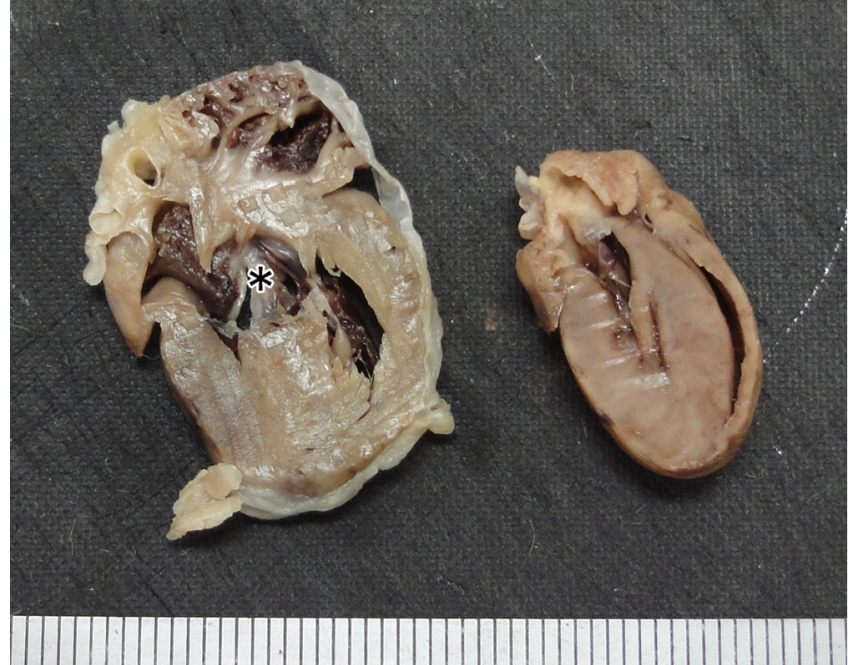

Fig. 2. On the reverse plane, the VSD heart (left) has an approximately $6 \mathrm{~mm}$ wide defect (asterisk) in the upper, membranous portion of the ventricular septum. The right side of the heart is normal (13-week-old).

Table 1. Free Wall Thickness of the Each Chamber and Septum Thickness (mm)

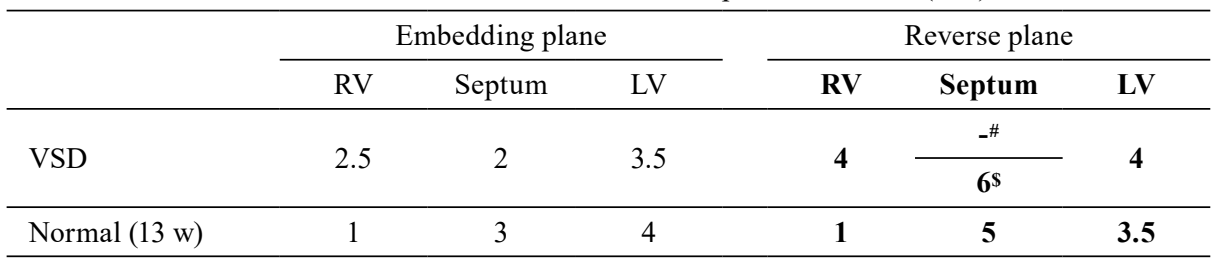

$\mathrm{RV}$; right ventricle, LV; left ventricle. ${ }^{\#}$ patent portion of the interventricular septum. ${ }^{\text {Snon-patent }}$ portion of the interventricular septum.

$3.5 \mathrm{~mm}$ for the right ventricle, septum, and left ventricle, respectively (Table 1 ). On the reverse plane, the heart had an approximately $6 \mathrm{~mm}$ wide defect in the upper, membranous portion and a $6 \mathrm{~mm}$ thick wall in the muscle portion of the ventricular septum (Fig. 2). The left and right ventricular walls measured $4 \mathrm{~mm}$ each in thickness, and the right ventricular wall was 4 times thicker than normal (Table 1). The left atrium was severely dilated $(12 \mathrm{~mm}$ in diameter in the histological section). The lungs showed a dark reddish change due to chronic congestion with a large amount of serosanguineous fluid (approximately $20 \mathrm{~mL}$ ) in the thoracic cavity. Perithymic lymph nodes showing a dark reddish change were 2 to 3 times larger than normal. The liver was severely enlarged and showed a dark reddish change. The abdominal cavity contained serosanguineous fluid (approximately $1.5 \mathrm{~mL}$ ). There were no lesions in the vertebral bones at autopsy.

Microscopic findings: The myocardial fibers were severely hypertrophic, 4 to 5 times larger than normal, in the right ventricle (Fig. 3) and mildly hypertrophic, 1.5 to 2 times larger than normal, in the left ventricle and septum (Fig. 4). Myocardial vacuolation was seen in the all chambers; however, both the atrium (Fig. 5) and right ventricle
(Fig. 3) were more severe than the others. The dilated left atrium was mildly congested and had mild hemorrhages with small numbers of hemosiderin-laden macrophages (Fig. 5). The severity of hemorrhage and macrophage infiltration in the right atrium was less than that in the left atrium. In the septum, focal myocardial necrosis with inflammatory cells infiltration (Fig. 6) and hyalinized myocardial fibers (Fig. 7) were recognized. Although the myocardial vacuolation was mild in the left ventricle, small foci of myocardial necrosis (Fig. 8) and fibrosis were found sporadically. Multifocal adhesive epicarditis was also present with mild edema (Fig. 9). No coronary artery disease or myocardial infarction was found. In the lung, the alveolar septa were thickened due to a large number of erythrocytes in the dilated capillaries or due to edema with small amounts of inflammatory cell infiltration. The alveolar spaces contained large numbers of hemosiderin-laden macrophages (heart failure cells) (Fig. 10). The liver showed severe centrilobular congestion with hepatocellular degeneration/necrosis and fibrosis indicative of passive venous congestion (Fig. 11). There was also moderate to severe congestion of the parathymic lymph node, spleen, and adrenal inner cortex. Interstitial edema was seen in the pancreas, prostate, and dermis of the whole 


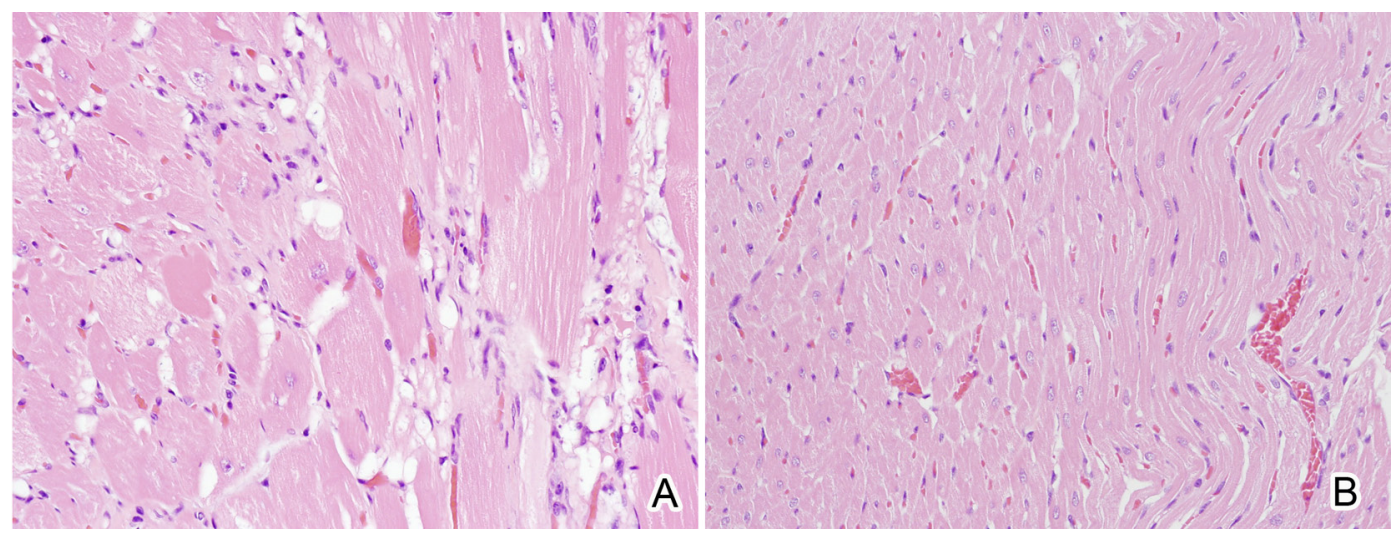

Fig. 3. Histopathology of the right ventricles in the VSD heart (A) and corresponding normal heart (B). The myocardial fibers of the VSD heart are severely hypertrophic with vacuolation. H\&E stain. $\times 400$.

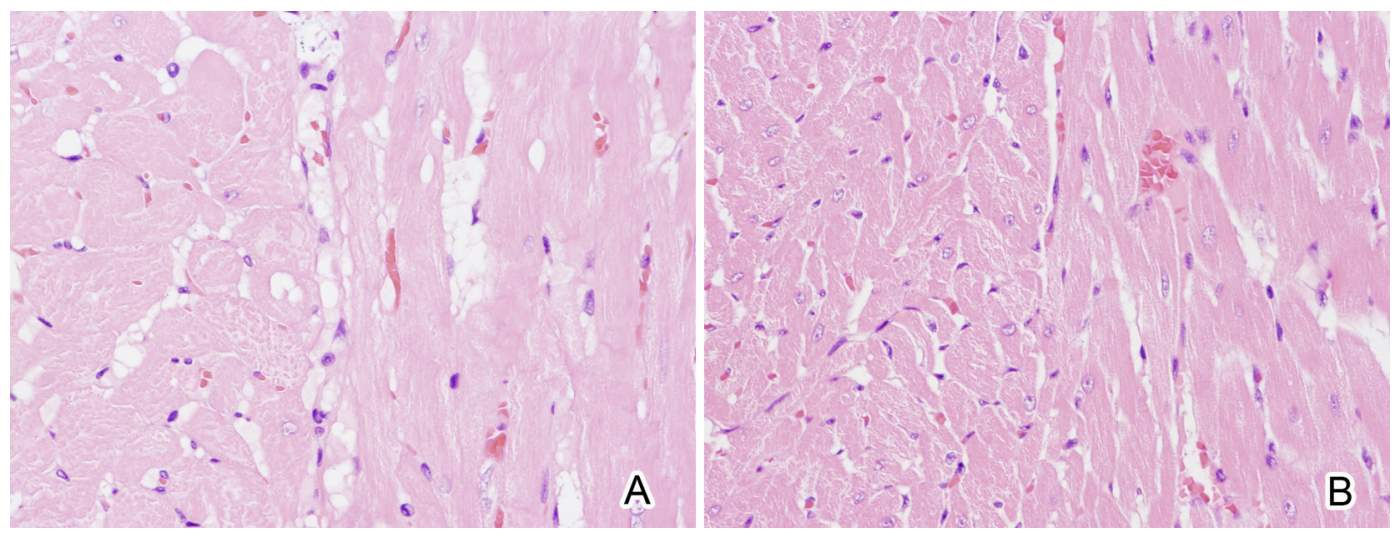

Fig. 4. Histopathology of the septum in the VSD heart (A) and corresponding normal heart (B). The myocardial fibers of the VSD heart are mildly hypertrophic with vacuolation. H\&E stain. $\times 400$.
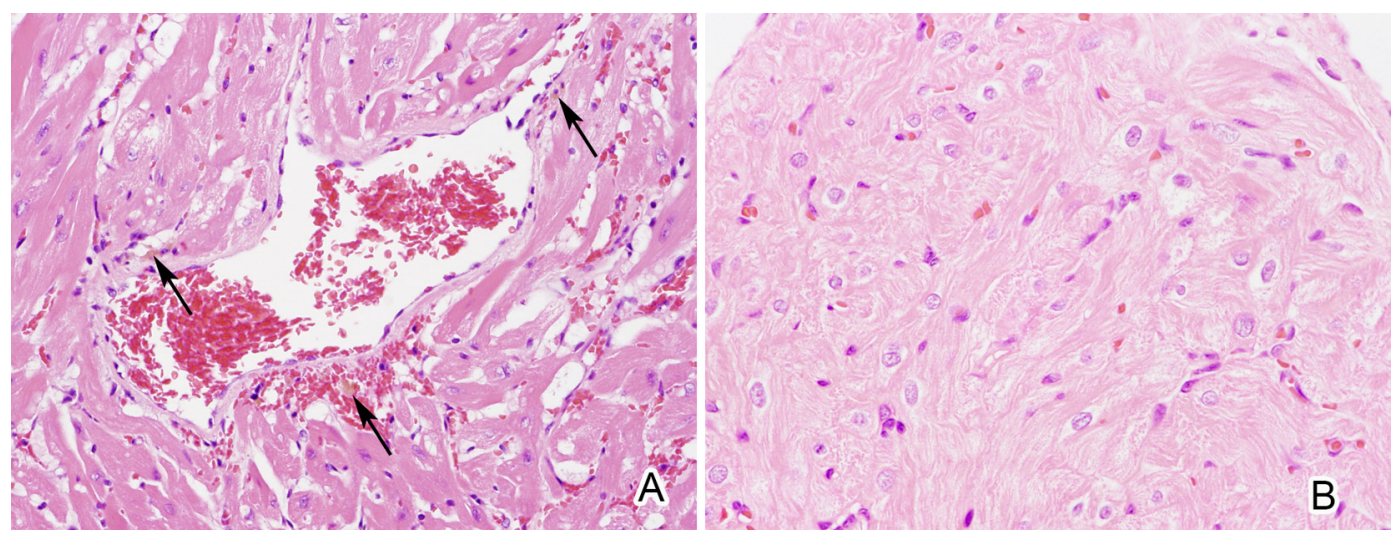

Fig. 5. Histopathology of the left atrium in the VSD heart (A) and corresponding normal heart (B). The dilated left atrium is mildly congested and has a small number of hemorrhages with hemosiderin-laden macrophages (arrows). H\&E stain. $\times 400$.

body. Moderate hyperplasia of erythrocytic hematopoietic cells was seen in the bone marrow of the femur and sternum. Atrophy was noted in the thymus, mesenteric lymph node, and white pulp of the spleen.
This report described a VSD in an adult $\mathrm{Crl}: \mathrm{CD}(\mathrm{SD})$ rat that was characterized macroscopically by a severe and wide defect of ventricular septa and microscopically by myocardial hypertrophy, vacuolation, necrosis with inflam- 


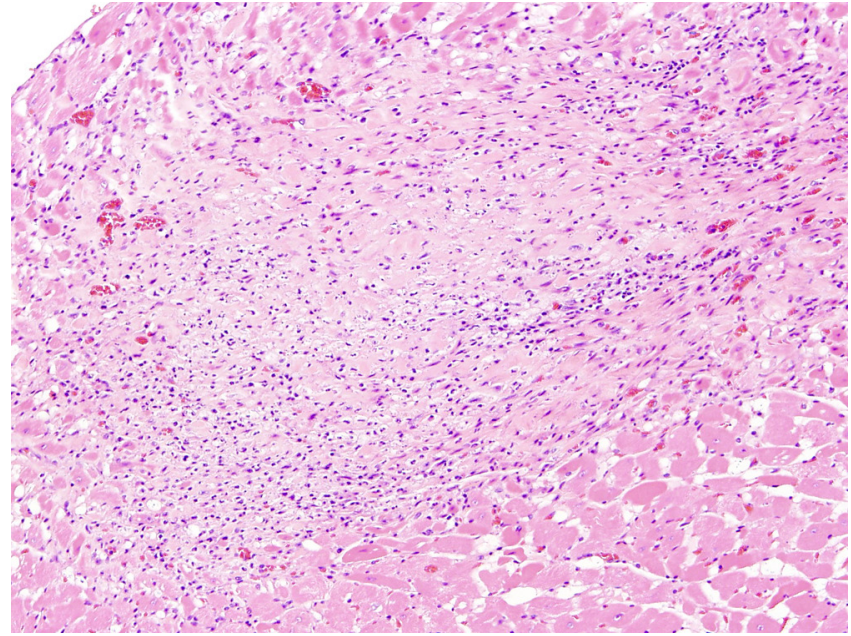

Fig. 6. Histopathology of the septum in the VSD heart. Focal myocardial necrosis with inflammatory cells infiltration is apparent. H\&E stain. $\times 200$.

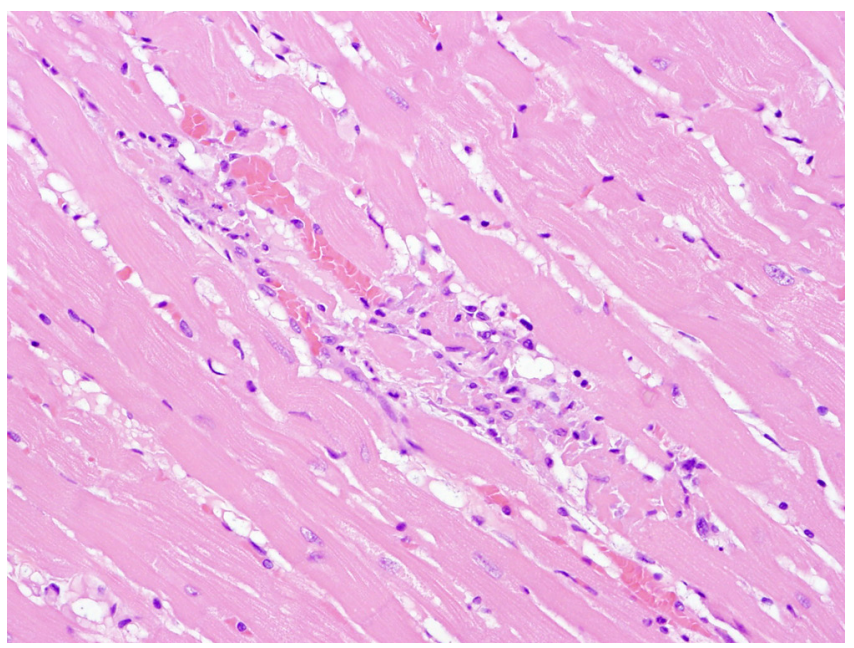

Fig. 8. Histopathology of the left ventricle in the VSD heart. Small foci of myocardial necrosis are sporadically apparent. H\&E stain. $\times 400$.

mation and hyalinization, and congestion and hemorrhage with hemosiderin-laden macrophages. It has been reported that histological examination of spontaneously occurring VSD in rats revealed no morphologic changes in the ventricular walls or any evidence of inflammation, fibrosis, or cytologic changes ${ }^{9-11}$. In contrast, myocardial changes are seen in various diseases. Abnormal metabolic, structural, and functional changes were found accompanied by hypertrophy that occurs in hypertension, obesity, and heart valve disease, after infarction, or with cardiomyopathy. Myocardial fiber damage takes the form of a cytoplasmic alteration such as vacuolation, and the irreversible consequence of myocyte damage is necrosis ${ }^{12}$. Necrosis is accompanied by a variable degree of inflammation ${ }^{12}$ and leads to cell loss

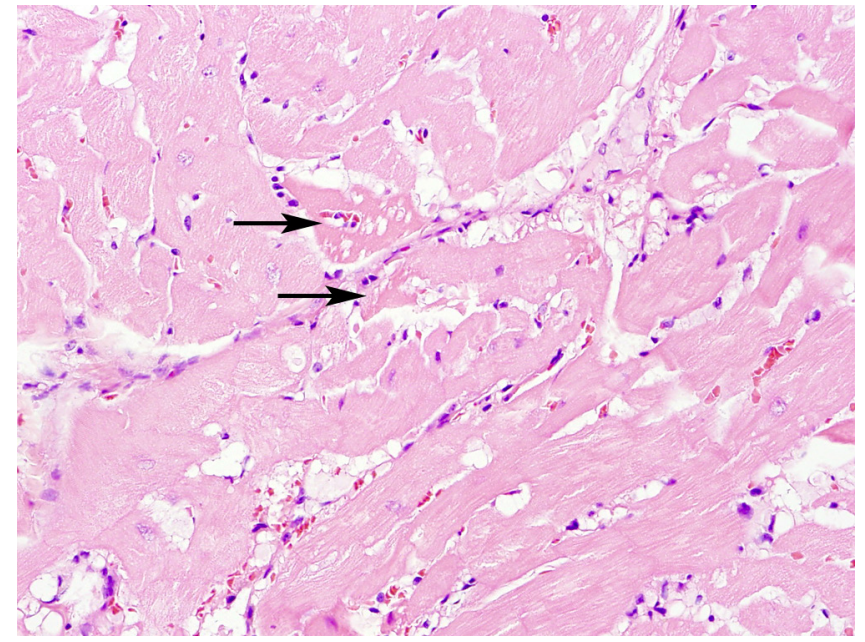

Fig. 7. Histopathology of the septum in the VSD heart. Myocardial vacuolation and hyalinized myocardial fibers (arrows) are slightly apparent. H\&E stain. $\times 400$.

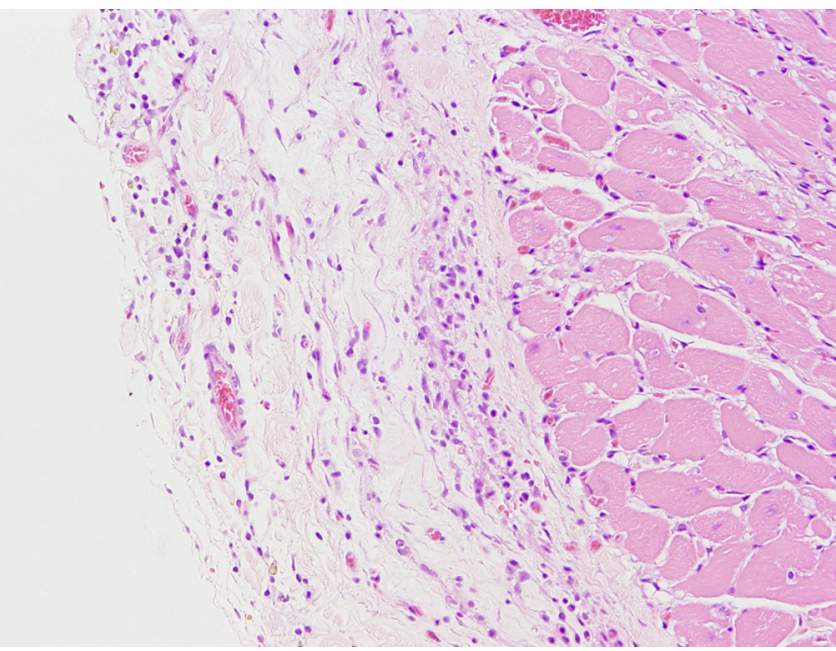

Fig. 9. Histopathology of the right ventricle in the VSD heart. Multifocal adhesive epicarditis is present with mild edema. H\&E stain. $\times 200$.

and fibrosis in all areas ${ }^{13}$. In degenerative myocardial disease, the lesion begins as coagulative necrosis of myocardial fibers, which become deeply eosinophilic and hyalinized with pyknotic nuclei ${ }^{13}$. Hemosiderin-laden macrophages are seen in the myocardium following hemorrhage or following repair of myocardial cell damage ${ }^{12}$. Although the changes in the present case do not seem to be specific or uniform in VSD rats, this study would yield new information on the detailed histological findings of VSD in adult rats.

VSD usually has a relatively benign clinical course in humans, either closing spontaneously or causing congestive heart failure treatable by surgery ${ }^{14}$. In patients with large defects, however, symptoms of congestive heart failure become evident in the first few weeks of life, and infants show 


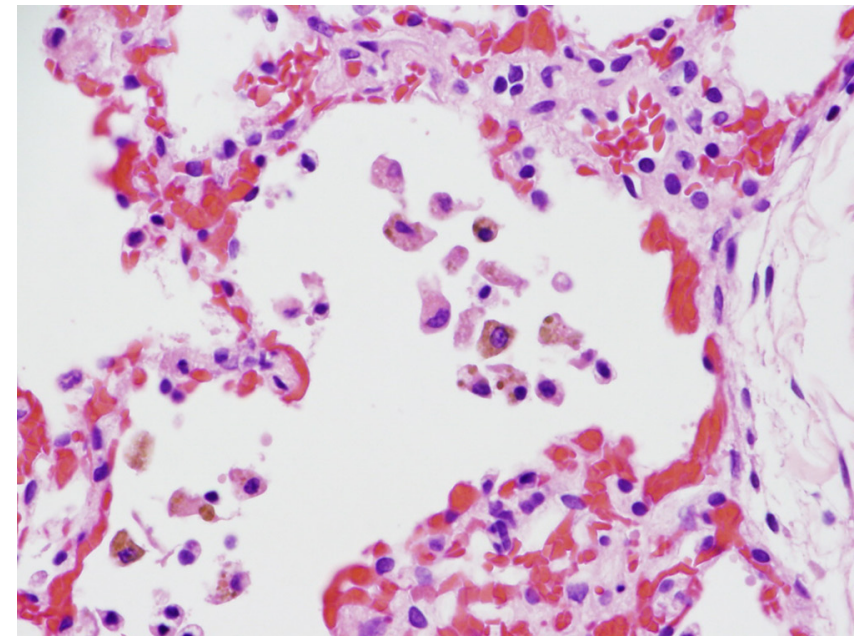

Fig. 10. Histopathology of the lung. The alveolar septa are thickened with a large number of erythrocytes in the dilated capillaries. The alveolar spaces contained large numbers of hemosiderinladen macrophages (heart failure cells). H\&E stain. $\times 800$.

high pulmonary blood flow and high pulmonary artery pressures, poor growth, rapid/labored breathing, tachycardia, and diaphoresis ${ }^{15}$. This case was apparently healthy and had no problems in terms of body weight gain until 3 days before death. It is uncertain why dyspnea and anorexia were noted and weight loss was recorded only 2 days before death.

The causes of congenital cardiovascular anomalies are varied. A great variety of environmental and genetic factors are probably responsible for this outcome in rats $1,16,17$. The pathogenic mechanism of the lesions detected in this case is speculated about below. As the right ventricular pressure equals the left ventricular pressure postnatally by left-to-right shunt in VSD, the right ventricle is confronted with a large systolic and diastolic load, which is followed by pulmonary hypertension with hypertrophy of the pulmonary arterioles upon histopathology ${ }^{16}$. The present case contained numerous hemosiderin-laden macrophages in the alveolar spaces, which indicated chronic passive congestion ${ }^{18}$, though hypertrophy of the pulmonary arterioles could not be distinguished. The liver showed passive venous congestion, which denotes elevation of pressure in the hepatic veins and venules relative to the pressure in the portal venules caused by congestive heart failure as a result of congenital cardiac disease ${ }^{19}$. These findings in this case are consistent with congenital cardiac disease (ventricular septal defect).

There is a surprising lack of information concerning the incidence of spontaneous VSD in these widely used $\mathrm{Crl}: \mathrm{CD}(\mathrm{SD})$ rats. VSD in adult rats may be seen more frequently than has been recognized in the past. We would like to request that pathologists and lab technicians using small ruminants including $\mathrm{Crl}: \mathrm{CD}(\mathrm{SD})$ rats pay more attention to not only necropsy but also to the process of making sections because VSD may be present even with no significant clinical histories.

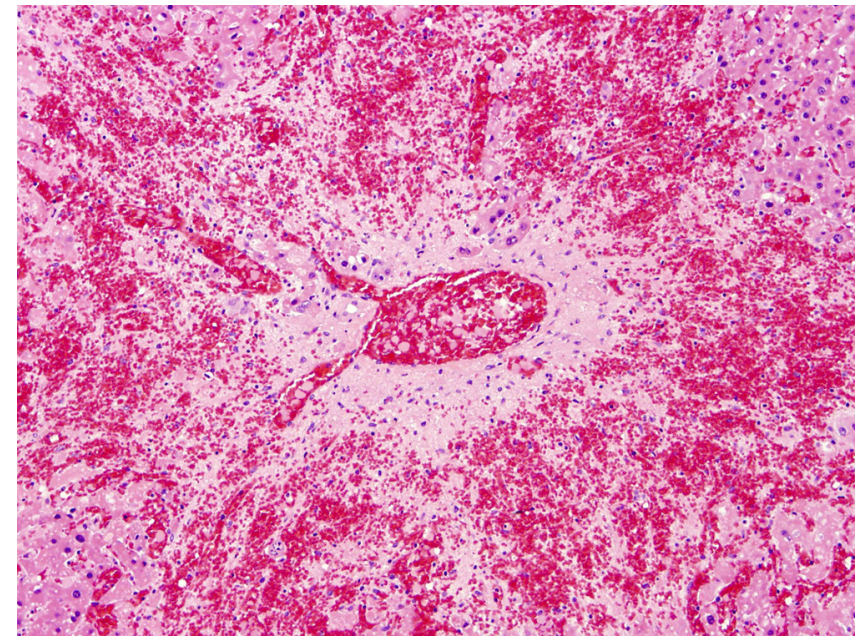

Fig. 11. Histopathology of the liver. The liver shows severe centrilobular congestion with hepatocellular degeneration/necrosis and fibrosis indicative of passive venous congestion. H\&E stain. $\times 200$.

Acknowledgements: The authors would like to thank Ms. Chie Shiromaru, Ms. Miwako Ishii, and Mr. Yuki Ikeda for the excellent technical assistance they provided. The authors also thank Mr. Stephan Kean Filiatrault, Ms. Kanae Tamatsukuri, and Mr. James Harada for language editing of the manuscript.

Disclosure of Potential Conflicts of Interest: The authors declare that they have no conflicts of interest.

\section{References}

1. Miller LM, Van Vleet JF, and Gal A. Disorders of domestic animals. Cardiovascular system and lymphatic vessels. In: Pathologic Basis of Veterinary Disease, 5th ed. JF Zachary, and MD McGavin, (eds). Elsevier Inc., Missouri. 564-575. 2012.

2. Haschek WM, Rousseaux CG, and Wallig MA. Selected malformations. Developmental pathology. In: Fundamentals of Toxicologic Pathology, 2nd ed. WM Haschek, CG Rousseaux, and MA Wallig (eds). Elsevier Inc., Missouri. 648-660. 2010.

3. Yadegari M, Babamohamadi K, and Goodarzi M. A case report of ventricular septal defect in a calf. Bulg J Vet Med. 15: 283-286. 2012.

4. Cappon GD, Fleeman TL, Cook JC, and Hurtt ME. Combined treatment potentiates the developmental toxicity of ibuprofen and acetazolamide in rats. Drug Chem Toxicol. 28: 409-421. 2005. [Medline] [CrossRef]

5. Fleeman TL, Cappon GD, and Hurtt ME. Postnatal closure of membranous ventricular septal defects in Sprague-Dawley rat pups after maternal exposure with trimethadione. Birth Defects Res B Dev Reprod Toxicol. 71: 185-190. 2004. [Medline] [CrossRef]

6. Gupta U, Cook JC, Tassinari MS, and Hurtt ME. Comparison of developmental toxicology of aspirin (acetylsalicylic 
acid) in rats using selected dosing paradigms. Birth Defects Res B Dev Reprod Toxicol. 68: 27-37. 2003. [Medline] [CrossRef]

7. Okuda H, and Nagao T. Cardiovascular malformations induced by prenatal exposure to phenobarbital in rats. Congenit Anom (Kyoto). 46: 97-104. 2006. [Medline] [CrossRef]

8. Aasa KL, Purssell E, Adams MA, and Ozolinš TR. In utero dimethadione exposure causes postnatal disruption in cardiac structure and function in the rat. Toxicol Sci. 142: 350-360. 2014. [Medline] [CrossRef]

9. Takano M, Ogawa E, Saitou T, Yamaguchi Y, Asano Y, Serikawa T, and Kuramoto T. Morphological features of adult rats of IS/Kyo and IS-Tlk/Kyo strains with lumbar and caudal vertebral anomalies. Exp Anim. 63: 269-275. 2014. [Medline] [CrossRef]

10. Johnson PD, Dawson BV, and Goldberg SJ. Spontaneous congenital heart malformations in Sprague Dawley rats. Lab Anim Sci. 43: 183-188. 1993. [Medline]

11. Solomon HM, Wier PJ, Fish CJ, Hart TK, Johnson CM, Posobiec LM, Gowan CC, Maleeff BE, and Kerns WD. Spontaneous and induced alterations in the cardiac membranous ventricular septum of fetal, weanling, and adult rats. Teratology. 55: 185-194. 1997. [Medline] [CrossRef]

12. Greaves P. Heart and pericardium. Cardiovascular system. In: Histopathology of Preclinical Toxicity Studies, 4th ed. $\mathrm{P}$ Greaves (ed). Elsevier, London. 263-288. 2012.

13. MacKenzie WF, and Alison R. Degenerative lesion. Heart.
In: Pathology of the Fischer Rat. GA Boorman, SL Eustis, MR Elwell, CA Montgomery, and WF MacKenzie, (eds). Academic Press, Inc., San Diego. 464-465.

14. Cohle SD, Balraj E, and Bell M. Sudden death due to ventricular septal defect. Pediatr Dev Pathol. 2: 327-332. 1999. [Medline] [CrossRef]

15. Sommer RJ, Hijazi ZM, and Rhodes JF Jr. Pathophysiology of congenital heart disease in the adult: part I: Shunt lesions. Circulation. 117: 1090-1099. 2008. [Medline] [CrossRef]

16. Grant Maxie M, and Robinson WF. Congenital abnormalities of the heart and large vessels. Cardiovascular system. In: Pathology of Domestic Animals. Vol. 3. G Maxie (ed). Elsevier Saunders, Philadelphia. 11-19. 2007.

17. Takano M, Katsumata Y, Ogawa J, Ebata T, Urasoko Y, Asano Y, Serikawa T, and Kuramoto T. Morphological features of mutant rat, IS-Tlk/Kyo, fetuses with caudal vertebral anomalies. Congenit Anom (Kyoto). 52: 42-47. 2012. [Medline] [CrossRef]

18. Lopez A. Diseases of the respiratory system. Respiratory system, mediastinum, and pleurae. In: Pathologic Basis of Veterinary Disease, 5th ed. JF Zachary and MD McGavin, (eds). Elsevier Inc., Missouri. 465-538. 2012.

19. Stalker MJ, and Hayes MA. Vascular factors in hepatic injury and circulatory disorders. Liver and biliary system. In: Pathology of Domestic Animals. Vol. 2. G Maxie (ed). Elsevier Saunders, Philadelphia. 333-336. 2007. 